\title{
Overexpression of microRNA-136-3p Alleviates Myocardial Injury in Coronary Artery Disease via the Rho A/ROCK Signaling Pathway
}

\author{
Yongbo Lin ${ }^{a}$ Hanliang Dan ${ }^{a}$ Jinguo Lu ${ }^{b}$
}

aDepartment of Cardiology, People's Hospital of Dongxihu District-wuhan, C,

${ }^{b}$ Department of Cardiology, Hospital of Traditional Chinese and

Province, Wuhan, China

\section{Keywords}

Coronary artery disease $\cdot$ MicroRNA-136-2. C.

EIF5A2 $\cdot$ Rho A/ROCK signaling pathw

\section{Abstract}

Objective: Coronary artery d: to human health, and the pathophysiological mect in the pathogenesis and identify the expre tional relevanc were inducer in $r$ by of overem sed
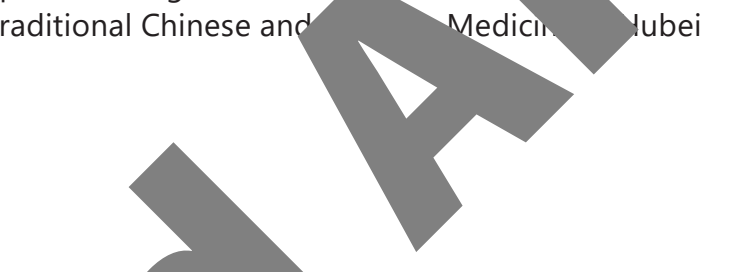

s'e, caro sms. Accurnulating evidence has implicated microRNAs (miRNAs) ent of cardiovascular diseases. The present study aims to 136-3p (miR-136-3p) in CAD and further investigate its func'ocyte apoptosis, oxidative stress and inflammatory response were assessed in ats. $\mathrm{h}$ diac microvascular endothelial cells (CMECs) were isolated and cultured by e expunt method, and the CMEC injury model was induced by homocysteine (HCY). of miR-136-3p in vitro was further evaluated. Results: miR-136-3p was poorly

ressed in the myocardial tissue of CAD rats and CMEC injury models. In vivo assays indiat that overexpressed miR-136-3p could improve cardiac function and alleviate pathologdamage in myocardial tissue, accompanied by reduced oxidative stress and inflammatory response. Moreover, in vitro assays suggested that overexpression of miR-136-3p enhanced

Yongbo Lin and Hanliang Dan are co-first authors. 
Kidney
Blood Pressure

Research
Kidney Blood Press Res 2020;45:477-496

\begin{tabular}{l|c|c|}
\hline DOI: 10.1159/000505849 & $\odot 2020$ The Author(s). Published by S. Karger AG, Basel
\end{tabular}

www.karger.com/kbr

Lin et al.: Functional Relevance of miR-136-3p in CAD

proliferation and migration while inhibiting apoptosis of HCY-stressed CMECs. Notably, we revealed that EIF5A2 was a target gene of miR-136-3p, and miR-136-3p inhibited EIF5A2 expression and activation of the Rho A/ROCK signaling pathway. Conclusion: In conclusion, the overexpression of miR-136-3p could potentially impede myocardial injury in vitro and in vivo in CAD through the blockade of the Rho A/ROCK signaling pathway, highlighting a poten miR-136-3p functional relevance in the treatment of CAD.

(C) 2020 The Author(s)

Published by S. Karger AG, Bacn

\section{Introduction}

Cardiovascular disease represents the most frequent cause of death 1 -dev $d$ regions, and the number of cardiovascular disease cases is also increasip or loping regions accompanied by economic growth [1]. As a common cardiovas y diseà conary artery disease (CAD) ranks as the first cause of mortality across the glo ing to the adverse clinical events [2]. The risk factors contributing to CAD h on well onized, such as high blood pressure, lipid disorders, cigarette smoking, a. te. wsica, hactivity [3, 4]. There is a paucity of evidence demonstrating the significan oxidative stress in the pathogenesis and development of cardiovascular disease. ading CAD [5]. In addition, the important role of inflammatory reaction ha. well esta ed during the progression

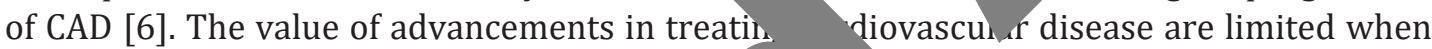
they fail to benefit those with the most urger a and the identification of effective biomarker associated with oxidative stress ar flam con could aid in improvement for the diagnosis and therapy of CAD.

MicroRNAs (miRNAs) represent a gy ily ur non-coding RNAs, which posttranscriptionally function as mediators of a va
untranslated region (UTR) o has been expanded to be ide? as critical mediators of not only physiological processes but also pathophysiolog ca. cardiovascular diseases [10, 11]. Interestingly, increasing studies have ovided evruence verifying altered levels of miRNAs in patients suffering from CAD, wh redict the occurrence of cardiovascular events [12, 13]. Specifically, the ? on of microRNA-136 (miR-136) in human vascular smooth muscle cells es $S$ on the development of atherosclerosis [14]. Moreover, the functional reley nce $\mathrm{iR}$ in vascular endothelial cell apoptosis has been previously demonstrated, ne a vascular endothelial cells are clearly associated with cardiovascylar dis [15]. He et al. [16] have found that miR-136-5p may act as a significant molecule moc. on of spinal cord injury lesions in rat models and may be useful for treating ase. A. other study has suggested that expression of miR-136-3p was elevated at $6 \mathrm{~h}$ chorionic gonadotropin administration in rat ovaries and rat granulosa cells Besides, through website prediction, eukaryotic translation initiation factor 5A2 A2) was verified as a target gene of miR-136-3p. It has been suggested that EIF5A2 d activate the Rho-kinase (ROCK) for enhancing the stress fibers formation [18]. It is reported that upregulation of EIF5A2 induces tumor metastasis in vivo by establishing an experimental mouse model [19]. Another study has revealed that $\mathrm{Mg}(\mathrm{II})$-Cat/si-EIF5A2 had a tumor inhibitory effect in a clinically relevant rat model of in-situ bladder cancer [20]. The Rho/ROCK signaling pathway plays a critical role in the occurrence of atherosclerosis and coronary vasospasm due to its control of endothelial function and the inflammatory reactions [21]. Therefore, we performed this study to detect the expression of miR-136-3p and EIF5A2 in rats and validate the hypothesis that miR-136-3p may be involved in the myocardial injury of CAD through its regulation on EIF5A2 and the Rho/ROCK signaling pathway. 
Kidney
Blood Pressure

Research
Kidney Blood Press Res 2020;45:477-496

\section{Materials and Methods}

\section{Ethics Statement}

All animal experiments were approved by the Ethics Committee of Hospital of Traditional Chinese and Western Medicine in Hubei Province and in accordance with the Regulations the Administration of Affairs Concerning Experimental Animals. All efforts were made to minimize the suffering of the animals included in the study.

\section{Experimental Animals and Grouping}

Sixty healthy male Sprague-Dawley rats were acclimated for 7 days and ther eig Then, 15 rats were randomly selected as the normal group. In the remainir $45 \mathrm{ra}$ dels of CAD were induced by high-fat diet and intraperitoneal injection of pi The el rats were fed a daily high-fat diet (30 g) for a total of 15 weeks, with freer. water during the experiment. Seventy-two hours before the last feeding, rats each $p$ were injected with pituitrin $(30 \mu \mathrm{g} / \mathrm{kg})$ once daily for 3 consecutive day en, the rats were fasted for $12 \mathrm{~h}$, followed by pathological examination of corona tery and heart of the normal group and the model group to confirm whe delin, was successful. Forty-five CAD rat models were randomly and evenly clas ed groups (15 rats in each group): CAD group (CAD rat models) ard CAD + nes control (NC) group (CAD rat models injected through the tail vein with irus once $\epsilon$ weeks for a total of 15 weeks), CAD + miR-136-3p group (CAD rat mode ected thr ugh the tail vein with virus overexpressing miR-136-3p once every 3 we al of 15 weeks). The virus overexpressing miR-136-3p was purchased from Sh hai chem Co., Ltd. (Shanghai, China). At the 15th week, the heart index was masu. rwards, the rats were injected with $10 \%$ potassium chloride ( $2 \mathrm{~min}$ ) thro, 11 emoral vein to stop the heart in the diastolic phase. After the blood was collected, 1 s removed, and the left and right ventricles were separated. After the re gb blotted, the left ventricle weight (LVW) and right ventricle weight (RVW) measured. The left ventricular weight index (LVWI) and right ventricular weight ex represent the ratio of LVW or RVW to the body weight.

\section{Hematoxylin Sta.}

The heart of ut and fixed in $10 \%$ formalin for $12 \mathrm{~h}$. The heart was cut open along the ligature and $\mathrm{m}$ ardial tissue under the suture was collected. The tissue was dehydrated in $30,9 \%$ gradient ethanol, and permeabilized in xylene (YB-8499, Shanghai Yubo B1 nology Co., Ltd., Shanghai, China). Then, the paraffin-embedded tissue was aous, into $4-\mu \mathrm{m}$-thick slices. After baking at $60^{\circ} \mathrm{C}$, the slice was dewaxed in xylene in an mydrated in 100, 95, 80, and 70\% gradient ethanol, respectively ( 5 min each ed by soaking in distilled water for 5 min. Hematoxylin (H8070, Solarbio, Beijing, ha) was adopted to stain the slice for $4 \mathrm{~min}$, followed by staining in eosin (E8090, Solarbio) ed with neutral balsam. The slices were observed and photographed under an optical microscope (DSX100, Olympus, Tokyo, Japan) to examine the staining results.

\section{Transmission Electron Microscopic Observation}

The rat myocardial tissue was fixed in $2.5 \%$ glutaraldehyde, followed by adding $1 \%$ citric acid. Then, tissue was dehydrated with gradient acetone, and embedded in Epon812 epoxy resin, followed by slicing by an ultramicrotome. After lead citrate staining, the pathological conditions of myocardial tissues were observed under a JEM-1400Plus electron microscope. 


\section{Kidney \\ Blood Pressure \\ Research}

\begin{tabular}{l|l}
\hline Kidney Blood Press Res 2020:45:477-496 \\
\hline DOI: 10.1159/000505849 & $\begin{array}{l}\text { @ 2020 The Author(s). Published by S. Karger AG, Basel } \\
\text { www.karger.com/kbr }\end{array}$ \\
\hline
\end{tabular}

Lin et al.: Functional Relevance of miR-136-3p in CAD

Transferase-Mediated Deoxyuridine Triphosphate-Biotin Nick End Labeling Staining

Transferase-mediated deoxyuridine triphosphate-biotin nick end labeling (TUNEL) kits (Beyotime Institute of Biotechnology, Nanjing, Jiangsu, China) were used to observe the apoptosis of cardiomyocytes. Paraffin section were dewaxed with xylene, hydrated with gradient alcohol and incubated with $20 \mu \mathrm{g} / \mathrm{mL}$ protease K (p6556, Sigma, St. Louis, MO, USA) solut: for $20 \mathrm{~min}$. The sections were incubated with $1 \times$ DNase I buffer for $5 \mathrm{~min}$ and DNase I buffe. containing $10 \mathrm{U} / \mathrm{mL}$ DNase I for $10 \mathrm{~min}$. Subsequently, the sections were incubated with 1 equipment buffer to incubate for $30 \mathrm{~min}$ and terminal deoxynucleotide transferase $(T$ incubation buffer for $60 \mathrm{~min}$ at $37^{\circ} \mathrm{C}$ in dark. Next, the sections were incubat yith $\mathrm{d}$ nobenzidine substrate solution, incubate for $10 \mathrm{~min}$, counterstained with hemat lin sealed. Image were analyzed under a light microscope.

\section{Spectrophotometric Colorimetric Determination}

The collected myocardial tissue was homogenized with pre-cooled $n$ a $10 \%$ homogenate. Then, the homogenate was centrifuged for $10 \mathrm{~m}$ natant. The contents of malondialdehyde (MDA) and roxide a tase (SOD) in myocardial tissue were examined by spectrophotometry.

\section{Measurement of Serum Factors}

Rats were anesthetized with pentobarbitar Im (50 mg Tyrrell Biotechnology Co., Ltd., Shanghai, China) via intraperitoneal injectio. $15 \mathrm{~min}$. '1. ve venous blood (15 mL) in the heart of each group was collected, the ser an sma of which were separated and stored for further use. All the rats in the gro vere sined for serum levels of cardiac function indices, including creatine kinas ${ }^{M B}$ ( cardiac troponin I (cTnI), and inflammatory factors interleukin (IL)-1 $\beta$, II , a umor necrosis factor- $\alpha$ (TNF- $\alpha$ ) by using an ELISA kit (Senxiong Biotech. Co., Lto gb China). Nitric oxide (NO) and endothelial nitric oxide synthase (eNOS bo Nanjing JianCheng Bioengineering Institute, Nanjing, China) were applied luate tne serum NO and eNOS contents. The contents of NO and eNOS were resp yely ed by nitrate reductase assay and a colorimetric method.

\footnotetext{
Reverse Tran ion Cative Polymerase Chain Reaction

Total RNA in tial tissue was extracted according to the instructions of a Trizol kit (15596-02 Invit ge aithersburg, MD, USA). The RNA was reversely transcribed into cDNA a ang instructions of the reverse transcription kit (K1621, Fermentas, H`nove, USA). The obtained cDNA was temporarily stored in a $-20^{\circ} \mathrm{C}$ refrigerator. The seq. $S$ of genes of interest and the internal references are displayed in Table 1 , vere sy sthesized by Shanghai GeneChem Co. Ltd., Shanghai, China. The expression of ach as measured by a real-time PCR kit (Takara, Dalian, China). A real-time PCR crument (ABI 7500, ABI, Foster City, CA, USA) was employed, with U6 and $\beta$-actin as housear $\mathrm{g}$ genes. The relative expression of each gene of interest was calculated by the $2^{-\Delta \Delta \mathrm{Ct}}$ nod, and each experiment was repeated 3 times. $\Delta \Delta \mathrm{Ct}=$ (average $\mathrm{Ct}$ value of the target group of the experimental group - average Ct value of the housekeeping gene of the experimental group) - (average Ct value of the target gene of the control group - average Ct value of the housekeeping gene of the control group). This method was also applicable to the detection of cellular expression levels.
}

Western Blot Assay

Myocardial tissue samples (50 mg) were cut into pieces and added with protein lysis buffer (R0010, Solarbio, Beijing, China), and homogenized at 3,000 r/min until being fully 
Kidney

Blood Pressure

Research

Table 1. Primer sequence for RT-qPCR

\begin{tabular}{l|l}
\hline Kidney Blood Press Res 2020;45:477-496 \\
\hline DOI: 10.1159/000505849 & $\begin{array}{l}\text { @ 2020 The Author(s). Published by S. Karger AG, Basel } \\
\text { www.karger.com/kbr }\end{array}$ \\
\hline
\end{tabular}

Lin et al.: Functional Relevance of miR-136-3p in CAD

lysed. After ice bath for $30 \mathrm{~min}$, the supernannt

Primer sequence

\begin{tabular}{|c|c|}
\hline miR-136-3p & $\begin{array}{l}\text { Forward: 5'-GGGGACATCATCGTCTCAAAT-3' } \\
\text { Reverse: 5'-CAGTGCGTGTCGTGGAGT-3' }\end{array}$ \\
\hline U6 & $\begin{array}{l}\text { Forward: 5'-GCTTCGGCAGCACATATA-3' } \\
\text { Reverse: 5'-CGCTTCACGAATTTGCGT-3' }\end{array}$ \\
\hline IL-1 $\beta$ & $\begin{array}{l}\text { Forward: 5'-GTTTGAGTCTGCACAGTTCCC-3' } \\
\text { Reverse: 5'-CAACTATGTCCCGACCATTGC-3' }\end{array}$ \\
\hline IL-6 & $\begin{array}{l}\text { Forward: 5'-TTCTTGGGACTGATGTT } \\
\text { Reverse: 5'-AATTAAGCCTCCGACTTGTC- }\end{array}$ \\
\hline TNF- $\alpha$ & $\begin{array}{l}\text { Forward: 5'-TGTCTGTGCCTCAC } \\
\text { Reverse: 5'-TTTGGGAACTTCTC, }\end{array}$ \\
\hline EIF5A2 & $\begin{array}{l}\text { Forward: 5'-CTGCTGACAGA } \\
\text { Reverse: 5'-CACTCATGGC }\end{array}$ \\
\hline$\beta$-Actin & 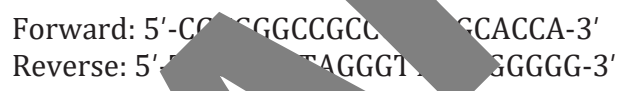 \\
\hline
\end{tabular}

leukin-6; TNF- $\alpha$, tymor necrosis

$-\alpha$; EIr5A2, eukaryotic trans-

at $4{ }^{\circ} \mathrm{C}$ for $15 \mathrm{~min}$. The protein concen acid Protein Quantitation Kit (23225, ford, IL, USA), which was adjusted to $1 \mu \mathrm{g} /$ $\mu \mathrm{L}$. The processed protein $\mathrm{a}$ a per well) and separated by $10 \%$ sodium dodecyl sulfate polyacrylami lectropnoresis (P1200, Solarbio). The separated protein sample was transferred poly ene fluoride membrane (HVLP04700, Millipore, Bedford, MA, USA) by th emi-dry erectrotransfer method, followed by Ponceau S staining (P0012, Solarbio) to ob ein transfer. After being blocked in 5\% skimmed milk powder at room $2 \mathrm{~h}$, the PVDF membrane was incubated with primary antibodies EIF5A2 spase-3, Bax, Bcl-2, RhoGEP, p-ROCK, $\beta$-actin (all 1: 1,000 and from Abcam, Carbridg UK Ad RhoA-GTP (1: 1,000, Cell Signaling Technology, Danvers, MA, USA) in ref overnight. After TBST rinsing 3 times (10 min each time), horser dish $P$ dase-labeled secondary antibody (1:2,000, ab6721, Abcam) was added and ced 1 at room temperature. The protein bands were visualized by diaminobenolution and photographed by a gel imager (Gel Doc XR, Bio-Rad, Hercules, CA, USA). the gray value of the protein of interest to that of the internal reference reprered the relative expression of the protein. This method was also applicable to the detection of Alar protein expression.

Isolation, Culture, and Characterization of Cardiomyocytes

Rat cardiac microvascular endothelial cells (CMECs) were isolated and cultured by the tissue explant method. The normal Sprague-Dawley rats were intraperitoneally anesthetized by sodium pentobarbital sodium ( $40 \mathrm{mg} / \mathrm{kg}$ ). Then, the rats were disinfected in $75 \%$ ethanol for $5 \mathrm{~min}$. The chest was opened layer by layer to expose the heart. The pericardium was cut open, and the heart was cut down from the ascending aorta and flushed by the D-Hanks balanced salt buffer to remove blood in the ventricles. The large blood vessels, the left and right atria, the right ventricle, and interventricular septum were removed, but the left ventricle 


\section{Kidney \\ Blood Pressure \\ Research}

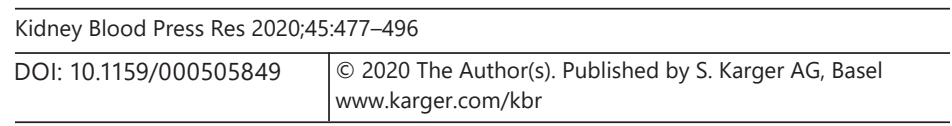

Lin et al.: Functional Relevance of miR-136-3p in CAD

was retained, with the endocardium and epicardium carefully removed. The remaining ventricular muscle was cut into pieces (about $1 \mathrm{~mm}^{3}$ ) by iris scissors and supplemented with $1 \mathrm{~mL}$ fetal bovine serum (FBS). Afterwards, the tissue blocks were evenly seeded in culture bottles treated with rat tail collagen. The tissues were incubated to allow cells to adhere to the bottle, and high-glucose Dulbecco's modified Eagle medium containing 20\% FBS $\mathrm{k}$ added $4 \mathrm{~h}$ later. After about $48 \mathrm{~h}$, there were cells growing around the tissue block, and plenty of cells grew around the tissue block 72-80 h later. The tissue blocks were removed, and th culture was continued for 36-48 h. After the cells settled at the bottom of the bottle, the were digested with $0.125 \%$ trypsin containing $0.02 \%$ ethylene diamine te scope (IX53, Olympus). High-purity CMECs were obtained through the differ 'ntivlat nent method: cells grew to confluence and were detached by trypsin until the rned d. The cell suspension was diluted by a complete medium and incubated for the ronadherent cells were removed and the medium was replaced. Next, the col vere aously incubated until they grew to confluence again, then the above steps $m$ peated twice. The obtained cells were high-purity rat CMECs.

Cell suspension was seeded on slide and allowed to g hich as then fixed for $30 \mathrm{~min}$, and incubated with blocking solution containing 0 . T $\quad \partial 0$ and $1 \%$ FBS for $1 \mathrm{~h}$ at room temperature. Subsequently, the cells were incuba ith CD31 primary antibody overnight at $4{ }^{\circ} \mathrm{C}$, followed by incubation with scent seco, y antibody at $37^{\circ} \mathrm{C}$ for 30 min. Then, cells were incubated with DAPI stain. $\quad$ lution at $/{ }^{\circ} \mathrm{C}$ for 30 min to stain the nucleus, followed by observation under a flu ou nicroscope (BX53, Olympus). The subsequent experiments were carried out usi ells à passage.

\section{Cell Modeling and Transfection}

The rat CMECs were incubated wit a CAD model. Model cells wer $p$ ed.

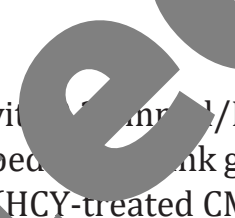

ar $y /$ L homocysteine (HCY) for $24 \mathrm{~h}$ to establish of any sequence), mimics NC $\quad$ HCY-treated CMECs transfected with the NC sequence of miR-136-3p mimics), and R-1. imics group (HCY-treated CMECs transfected with miR-136-3p mimics, pu sed from snanghai GenePharma Co., Ltd., Shanghai, China). The cells were seeded in cultu $0 \mathrm{~mL}$ ), and the cells were grown to a confluence of $30-50 \%$ in complete med otides were pr arf lipofectamine 2,000 + $100 \mu \mathrm{L}$ serum-free medium (5 min at room temperatur ); mi 36 mimics or mimics NC $(50 \mathrm{nmol})+100 \mu \mathrm{L}$ serum-free medium (at room ter atur $0 \mathrm{~min}$ to form the complex of liposome). The cells were washed in s rum- $\mathrm{h}$ edium in the culture flask. The complex was incubated with antibiotics and free ym for transfection at $37^{\circ} \mathrm{C}$ in a $5 \% \mathrm{CO}_{2}$ incubator. The medium was renewed

a terby omplete medium and further incubated for the following experiments.

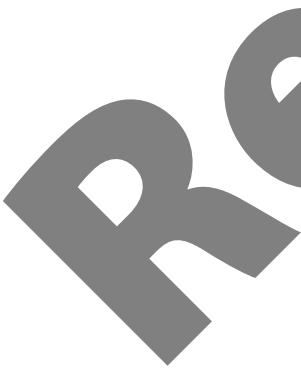

\section{Cell Viability Assay}

hen the transfected CMECs reached $80 \%$ confluence, the cells were routinely trypLed and pipetted into a single cell suspension. After cell counting, the cells were seeded in a 96-well plate $\left(3 \times 10^{3}\right.$ to $6 \times 10^{3}$ cells per well). The volume of each well was $200 \mu \mathrm{L}$, and each group was repeated in 6 wells. After incubation at $37^{\circ} \mathrm{C}$ in a $5 \% \mathrm{CO}_{2}$ incubator for $24-72$ $\mathrm{h}$, the cells were treated with 3-(4,5-dimethyl-2-thiazolyl)-2,5-diphenyl-2-H-tetrazolium bromide (MTT) solution ( $5 \mathrm{mg} / \mathrm{mL}$, Sigma, $20 \mu \mathrm{L}$ per well). Following another incubation at $37^{\circ} \mathrm{C}$ in a $5 \% \mathrm{CO}_{2}$ incubator for $4 \mathrm{~h}$, the incubation was terminated, and the culture medium was discarded. Dimethyl sulphoxide $(150 \mu \mathrm{L})$ was added to dissolve the crystal. After 24, 48 and $72 \mathrm{~h}$, the absorbance of each well was measured on an ELISA microplate reader. The MTT curves were plotted, with the absorbance as the ordinate and the time as the abscissa. 


\section{Kidney \\ Blood Pressure}

Research

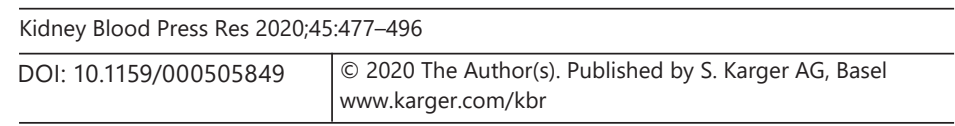

Lin et al.: Functional Relevance of miR-136-3p in CAD

\section{Flow Cytometric Detection of Cell Cycle Progression and Apoptosis}

Propidium iodide (PI) single staining assay: $48 \mathrm{~h}$ after transfection, CMECs cells of each group were detached by $0.25 \%$ trypsin and centrifuged at $4{ }^{\circ} \mathrm{C}, 1,000 \mathrm{r} / \mathrm{min}$ for $5 \mathrm{~min}$, with the supernatant discarded. Then, the cells were resuspended in phosphate buffered saline (PBS), with the cell concentration adjusted to about $1 \times 10^{5}$ cells $/ \mathrm{mL}$. Following this, the ce were fixed in $2 \mathrm{~mL}$ of pre-cooled $75 \%$ ethanol at $4{ }^{\circ} \mathrm{C}$ for $30 \mathrm{~min}$ and centrifuged to discarc the ice ethanol. Then, $100 \mu \mathrm{L}$ RNase A was added for a $37^{\circ} \mathrm{C}$ water bath for 30 min avoidj the light exposure. The cells were incubated with $400 \mu \mathrm{L}$ PI staining solution (P4170, Si USA) for $30 \mathrm{~min}$ at $4{ }^{\circ} \mathrm{C}$. A flow cytometer (Gallios, Beckman Coulter, S. Kraer Boul Brea, CA, USA) was adopted to examine the red fluorescence excited at $488 \mathrm{~nm}$ fo ll co detection.

Annexin V fluorescein isothiocyanate (FITC)/PI double staining assay, fection, CMECs of each group were detached by EDTA-free $0.25 \%$ trypsin a. the flow tube. Cells were centrifuged with the supernatant discarded. Acc ing to istructions of an Annexin-V-FITC Apoptosis Detection Kit (K201-100, Biovls ISA), the AnnexinV-FITC, PI, hydroxyethyl piperazine ethanesulfonic acid $(H$ buffer ion was formulated into Annexin-V-FITC/PI dye solution at a ratio of $1: 2 \quad \square \rho \mathrm{L}$, wquot of the dye solution was adopted to resuspend $1 \times 10^{6}$ cells, which we or $15 \mathrm{~min}$ at room temperature. Then, $1 \mathrm{~mL}$ of HEPES buffer solution was added, nixed by shaking. With the excitation wavelength at $488 \mathrm{~nm}$, a flow cytom vas employ o determine FITC fluorescence by a $515 \mathrm{~nm}$ band-pass filter, and PI fluores by a $620 . \mathrm{m}$ band-pass filter, in order to detect cell apoptosis.

\section{Transwell Migration Assay}

After $72 \mathrm{~h}$ of transfection, the $\mathrm{CM} \leadsto$ conected and prepared for cell suspension. The cells were seeded in the upper Tra in a $37^{\circ} \mathrm{C} 5 \% \mathrm{CO}_{2}$ incubator h. hat failed to penetrate the membrane in the upper chamber were gently $\mathrm{V}$ ff witn a cotton swab. The penetrated cells were fixed in 95\% ethanol for 15-20 m and with crystal violet dye for $10 \mathrm{~min}$. The cells on the back of the membrane w observea,photographed and counted under a high magnification inverted microscope. Ti number of cells in each sample was calculated from 5 randomly select number of cells passing through the polycarbonate membrane of ${ }^{1}$ vas used as an index for evaluating the migration ability.

\section{Dua ${ }^{\mathrm{N}}$ fera orter Gene Assay}

The ible target genes of miR-136-3p were predicted based on online analysis re, 9 TargetScan, miRanda, MiRbase, and Pictar. EIF5A2 3'UTR wild-type e (EIF A2-3'-UTR-WT) and EIF5A2 3'UTR mutant sequence (EIF5A2-3'-UTR-MUT) ed and synthetized by Shanghai Generay Biotech Co., Ltd. (Shanghai, China). The

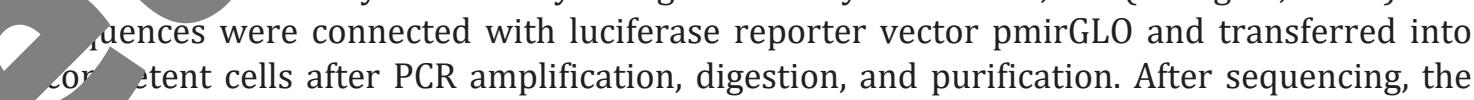
SA2-WT and EIF5A2-MUT plasmids were obtained (constructed by Generay Biotech), which were then transfected into the HEK293 cell line. The luciferase activity was measured by dual luciferase reporter gene assay reagent (Promega, USA). After $48 \mathrm{~h}$ of transfection, the original medium was removed, and cells were washed twice with PBS. Then, $100 \mu \mathrm{L}$ of passive lysis buffer was added to each well of the cells and shaken for $15 \mathrm{~min}$ at room temperature to collect the cell lysate. The program was set to pr-read for $2 \mathrm{~s}$, and the reading process lasted for $10 \mathrm{~s}$. The prepared LARII, Stop \& Glo ${ }^{\circledR}$ Reagent was added to the luminescent plate of the cell lysate $\left(20 \mu \mathrm{L}\right.$ per sample) and placed in a Modulus ${ }^{\mathrm{TM}}$ luminometer (Turner BioSystems, USA) for detection. 

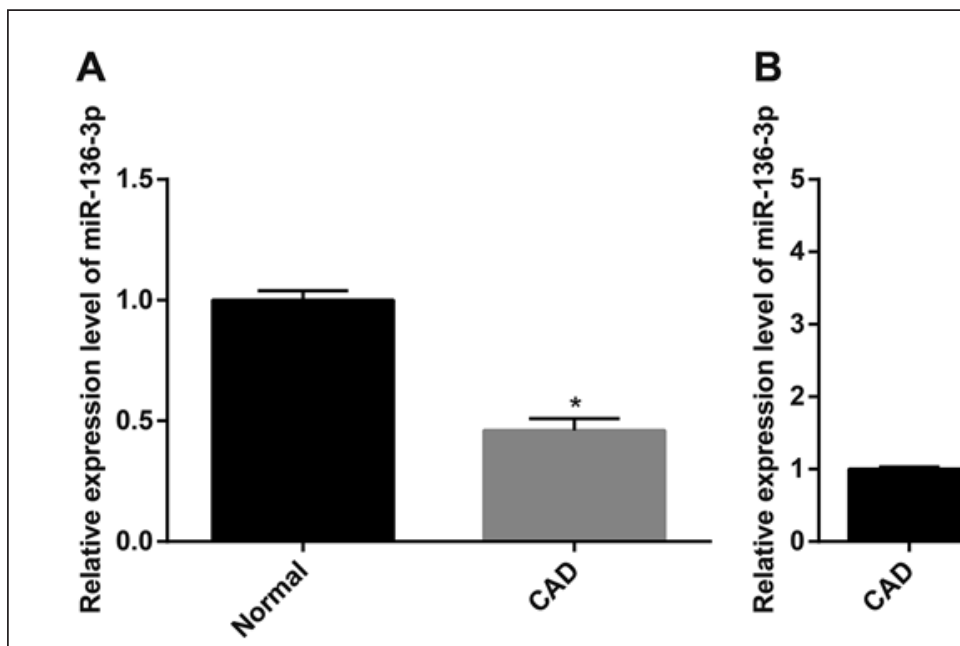

Fig. 1. Expression levels of miR-136-3p in the myocardial tissue of rat. miR-136-3p in the myocardial tissue of normal rats an LD rats. B Exp myocardial tissue of rats in each group with overexpres $\quad$ miR-136-3 gro . A Expression levels of ion levels of miR-136-3p in the groups were performed by the $t$ test, and comparisons am. by pairwise comparison with the least significant diffe vs. the CAD group.

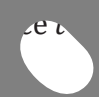

tiple groups by on $p<0.05$ vs. the normal group. ${ }^{*} p<0.05$

Statistical Analysis

The data were processed The Kolmogorov-Smirnov tes bution. The results were $e$ groups were performed analysis of variance (AN the $t$ test $S S$ C stical software (IBM Corp, Armonk, NY, USA). sed to aetermine whether the data were in normal distri(as an \pm standard deviation. Comparisons between two test, and comparisons among multiple groups by one-way red by pairwise comparison with the Fisher's least significant difference + The alest was considered significant if $p<0.05$.<smiles>[C+]1[C+]=C[CH]1</smiles>

\section{R-13 Is Poorly Expressed in the Myocardial Tissue of CAD Rats}

resuı of reverse transcription quantitative polymerase chain reaction (RT-qPCR) ver expression of miR-136-3p in the myocardial tissues of modeled rats than that

ne normal rats $(p<0.05$ ) (Fig. 1A), suggesting that miR-136-3p may be involved in the oc lence of CAD. The expression of miR-136-3p in the myocardial tissues did not differ Ificantly between the CAD group and the CAD + NC group $(p>0.05)$. Compared with the CAD group and the CAD + NC group, the CAD + miR-136-3p group showed elevated expression of miR-136-3p in the myocardial tissue of the rats $(p<0.05)$ (Fig. 1B), indicating that the virus overexpressing miR-136-3p successfully altered the miR-136-3p expression.

\section{Overexpression of miR-136-3p Improves Cardiac Function and Alleviates Pathological}

Damage in the Myocardial Tissue of CAD Rats

The results of the cardiac function index measurement (Table 2) identified higher LVWI and RVWI in CAD rats than that in the normal rats $(p<0.05)$. The CAD group and the CAD + 
Kidney

Blood Pressure

Research

Table 2. The effect of miR-136-3p on the cardiac function index of rats

\begin{tabular}{l|l}
\hline Kidney Blood Press Res 2020;45:477-496 \\
\hline DOI: 10.1159/000505849 & $\begin{array}{l}\text { @ } 2020 \text { The Author(s). Published by S. Karger AG, Basel } \\
\text { www.karger.com/kbr }\end{array}$ \\
\hline
\end{tabular}

Lin et al.: Functional Relevance of miR-136-3p in CAD

\begin{tabular}{lll}
\hline Group & LVWI, mg/g & RVWI, mg/g \\
\hline Normal & $3.01 \pm 0.23$ & $0.65 \pm 0.09$ \\
CAD & $4.79 \pm 0.58^{*}$ & $1.31 \pm 0.17^{*}$ \\
CAD+NC & $4.86 \pm 0.46^{*}$ & $1.35 \pm 0.12^{*}$ \\
CAD+miR-136-3p & $3.93 \pm 0.49^{*}, \#$ & $0.96 \pm 0.07^{*}, \#$ \\
\hline
\end{tabular}

CAD, coronary artery disease; NC, negative control; LVWI, ventricular weight index; RVWI, right ventricular weight index. 0.05 vs. the normal group. ${ }^{\#} p<0.05$ vs. the CAD grour

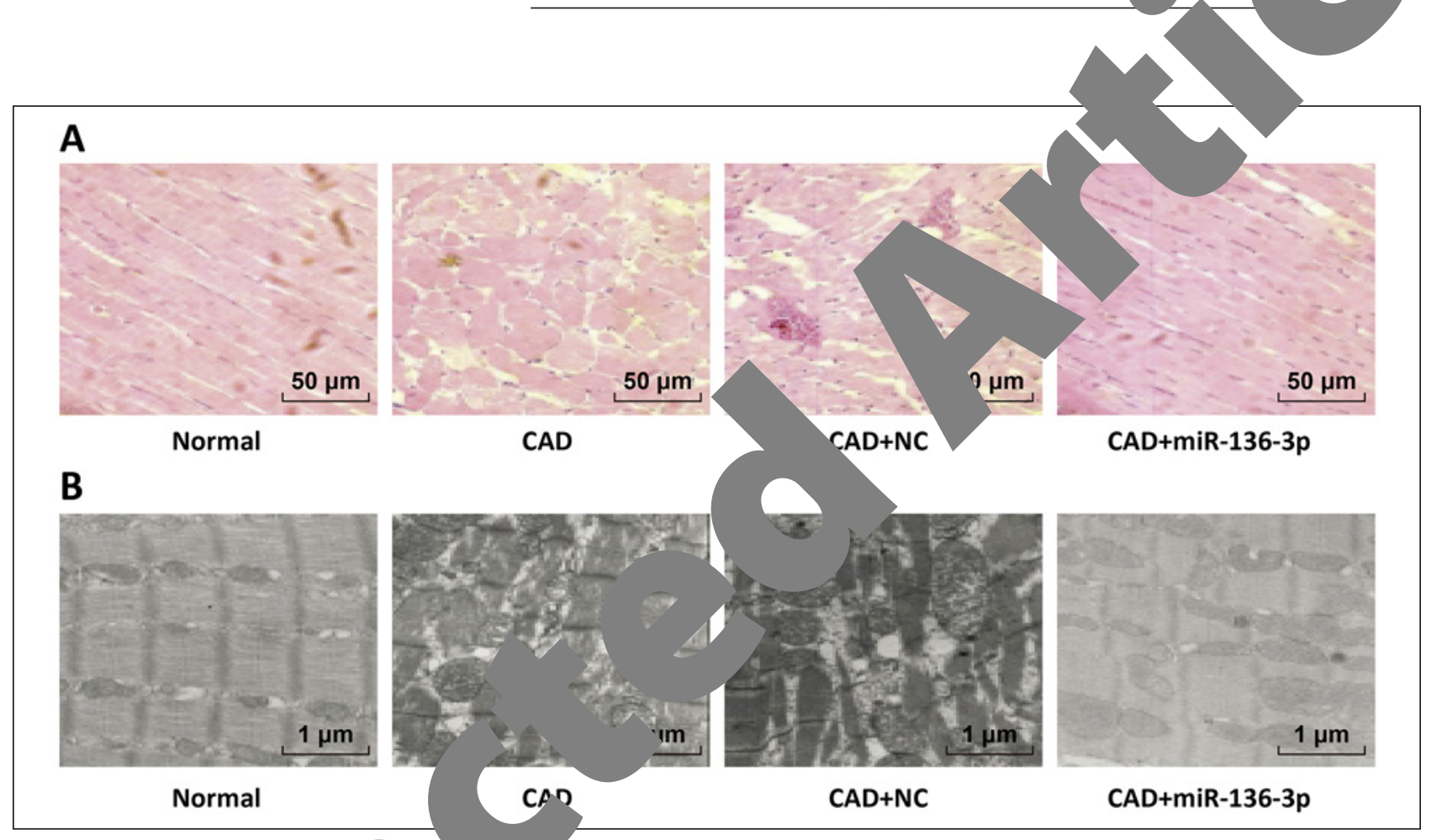

Fig. 2. Overexpre myocardial tissu if 1 HE staining to observe the pathological condition of myocardial tissue in each group $\left(\mathrm{O}_{0}\right.$. . $\mathrm{n}$ sion electron microscopic observation of the ultrastructure of myocardial tissue in ear ap $(x+, n=5$.

o showed no significant difference in LVWI and RVWI $(p>0.05)$. Compared with the AD . and CAD + NC group, LVWI and RVWI in the CAD + miR-136-3p group were erved with significant degradation $(p<0.05)$, indicating that virus overexpressing miR$13 . \rho$ affected the cardiac function of CAD rats.

Hematoxylin-eosin staining was conducted to observe the pathological changes of myocardial tissues (Fig. 2A). The normal group showed neatly arranged myocardial fibers, clear cross striation, as well as continuous and intact myocardium and endocardial cells. Besides, the nucleus was in the middle, and the cytoplasm was evenly stained. No interstitial edema, cell swelling, or inflammatory cell infiltration was observed. In the CAD group and the CAD + NC group, we could observe disordered myocardial fibers and cardiomyocytes, with abnormal structures. The interstitial was moderately swollen, the inflammatory cells infiltrated, and the cytoplasm was unevenly stained. Moreover, the CAD + miR-136-3p group displayed mild pathological damage, with neatly arranged myocardial fibers. Additionally, 


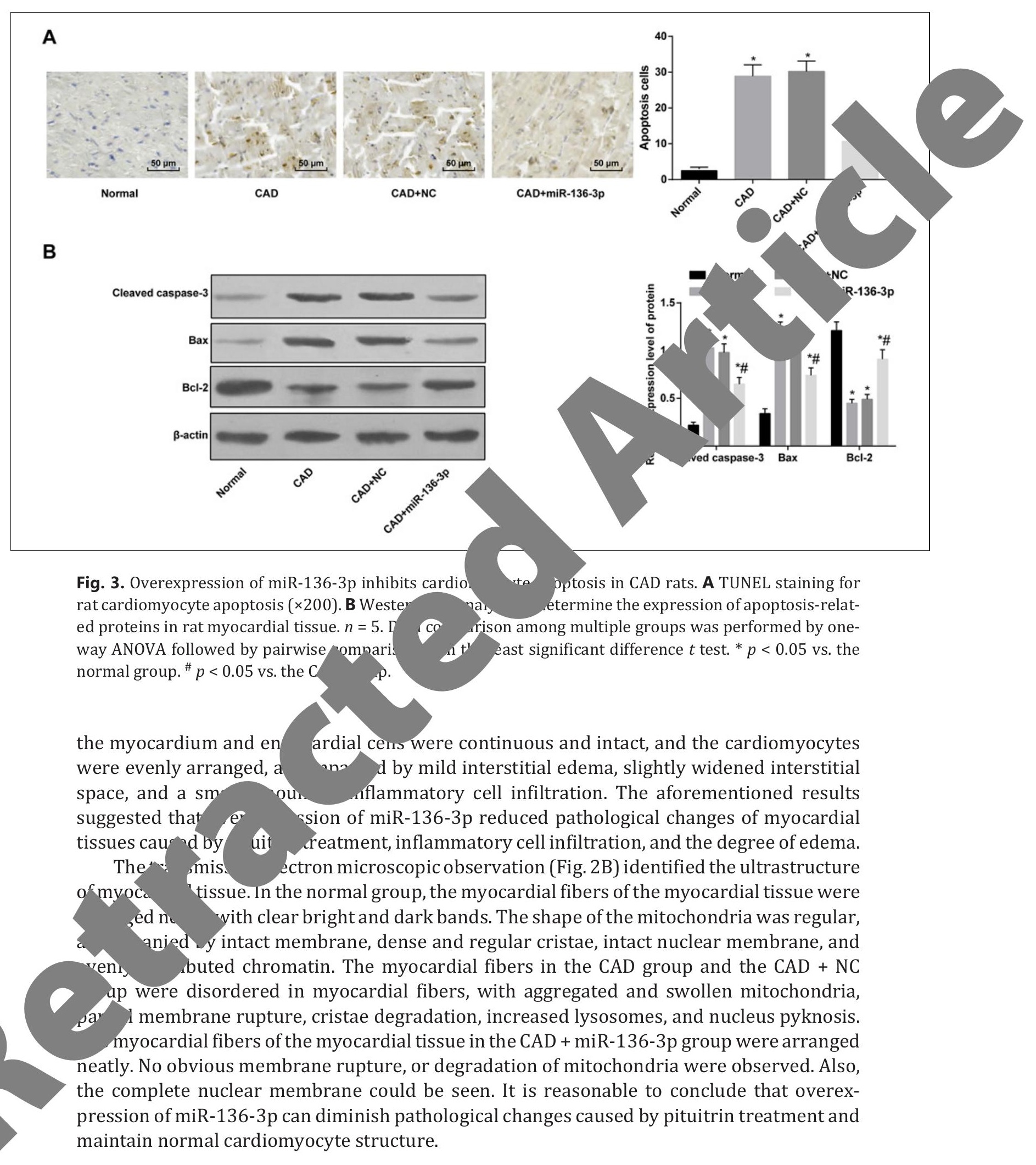

Overexpression of miR-136-3p Inhibits Cardiomyocyte Apoptosis in CAD Rats

The apoptosis conditions of cardiomyocytes were observed following TUNEL staining (Fig. 3A). There were fewer apoptotic cardiomyocytes in the myocardial tissue of the normal 


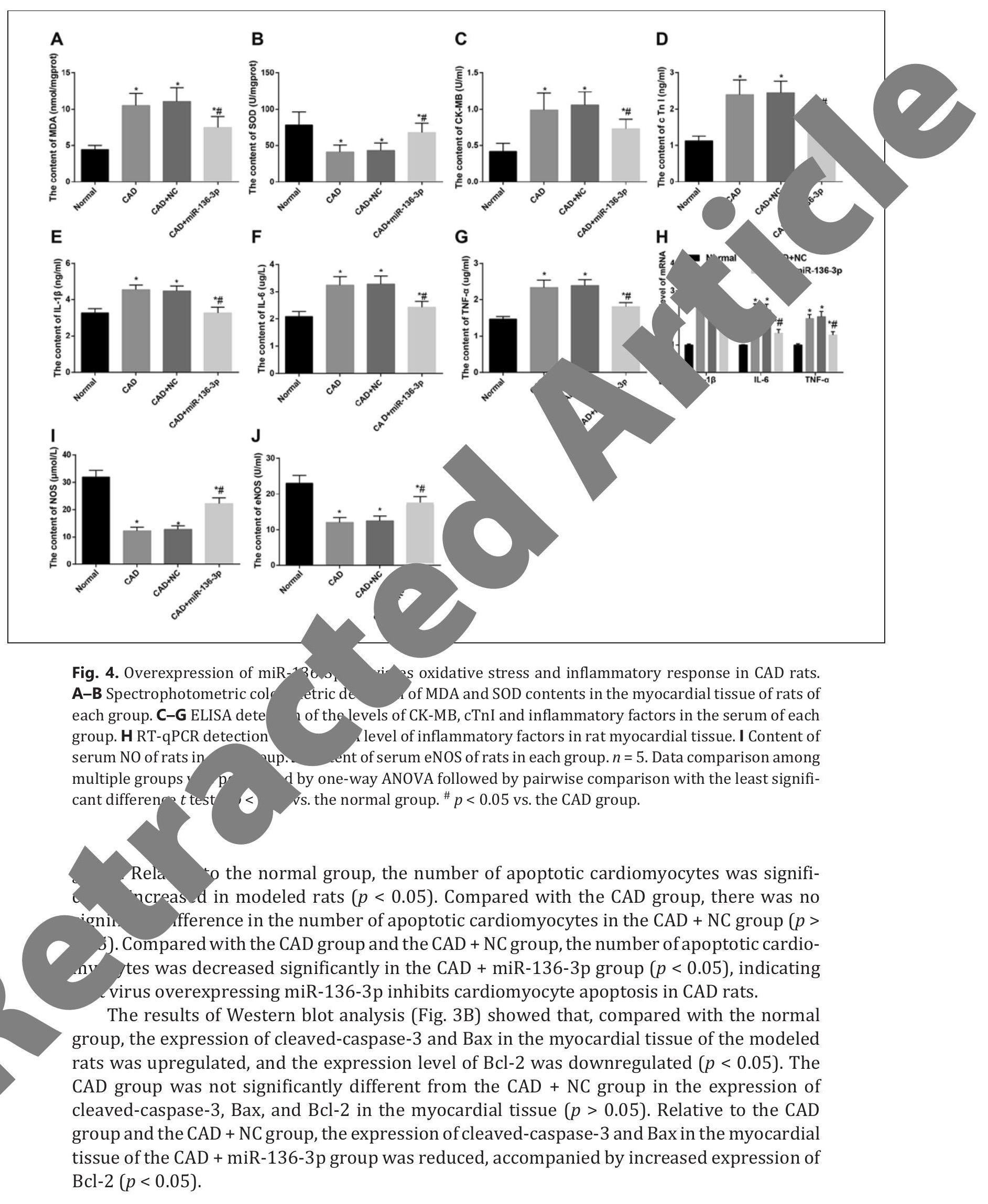


A

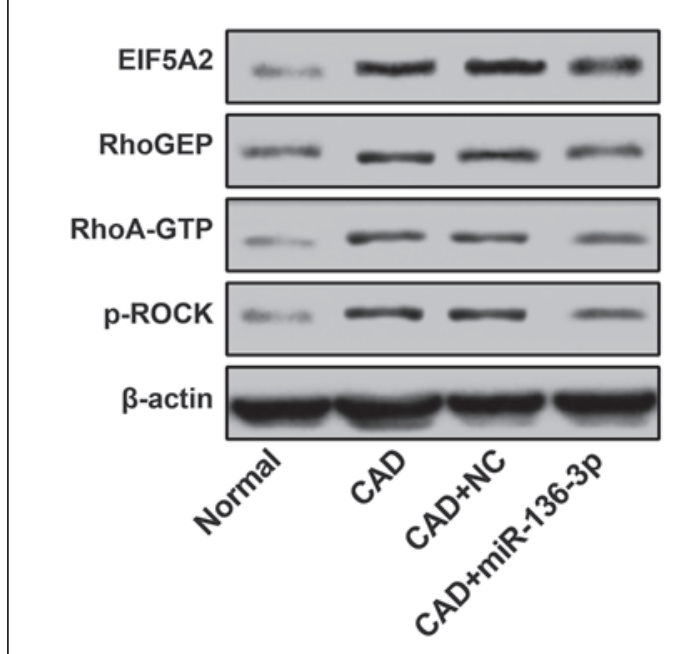

B

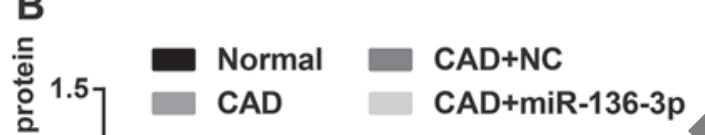

Fig. 5. MiR-136-3p inhibits EIF5A2 expression and ac ion of the Rh ROCK signaling pathway in the myocardial tissue of CAD rats. A Protein bands of EIF5, oGEP, Rho $P$, and p-ROCK in the myocardial tissue of rats in each group. B Expression of EIF5A2 RhoA-GTP, and p-ROCK in the myocardial tissue of rats in each group. $n=5$. Data comparison am mu roups was performed by one-way ANOVA followed by pairwise comparison with the least fican crence $t$ test. ${ }^{*} p<0.05$ vs. the normal group. ${ }^{\#} p<0.05$ vs. the CAD group.

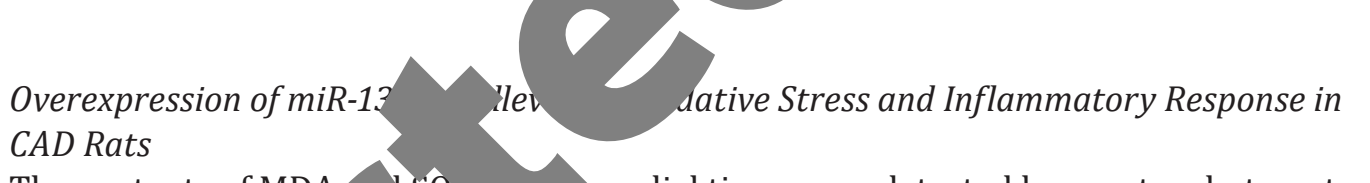

The contents of MDA SOL $\quad$ cardial tissue was detected by spectrophotometry (Fig. 4A-B). Increased M content anu decreased SOD content were found in the myocardial tissue of modeled rats, $m r$ with the normal rats (both $p<0.05$ ). The CAD group showed no signif $\quad$ In MDA and SOD contents from the CAD + NC group (all $p>$ 0.05). Compar w CAD and CAD + NC groups, upregulated SOD content and downregulated MDACO ant $r$ shown in the myocardial tissue of the CAD + miR-136-3p group (both $p<9$.It ated that upregulation of miR-136-3p could alleviate oxidative stress in iury in rats.

e le $\mathrm{CK}-\mathrm{MB}$, cTnI, and inflammatory factors IL-1 $\beta$, IL-6, and TNF- $\alpha$ in the of eac. group were measured by ELISA (Fig. 4C-G). Compared with the normal roup crum levels of CK-MB, cTnI, IL-1 $\beta$, IL-6 and TNF- $\alpha$ were increased in the other aps with modeled rats $(p<0.05)$. There was no significant difference in the serum ey of CK-MB, cTnI, IL-1 $\beta$, IL-6, and TNF- $\alpha$ between the CAD and CAD + NC groups (all 0.05). Moreover, the CAD + miR-136-3p group displayed reduced serum levels of CK-MB, cTnI, IL-1 $\beta$, IL-6, and TNF- $\alpha$, in comparison with the CAD and CAD + NC groups (all $p<0.05)$, indicating that upregulation of miR-136-3p can reduce the inflammatory response in the serum of CAD rats.

At the same time, RT-qPCR was adopted to determine the expression of inflammatory factors IL-1 $\beta$, IL-6, and TNF- $\alpha$ in the myocardial tissue of each group (Fig. 4H). Higher expression of IL-1 $\beta$, IL- 6 and TNF- $\alpha$ was identified in the myocardial tissue of modeled rats than that in the normal rats (all $p<0.05$ ). Compared with the CAD group, the expression of IL-1 $\beta$, IL-6, and TNF- $\alpha$ in the myocardial tissue of CAD + NC group was not significantly 


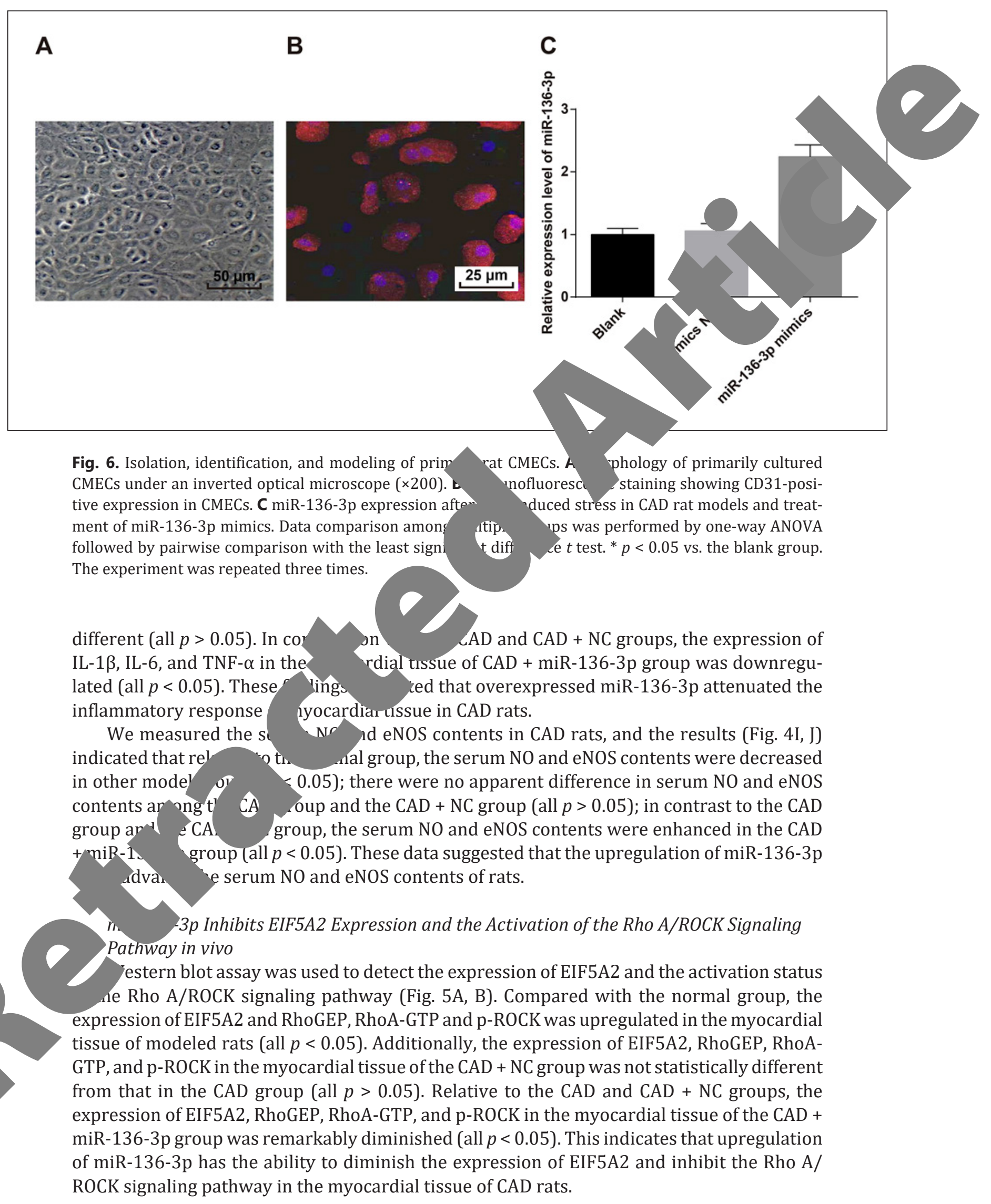




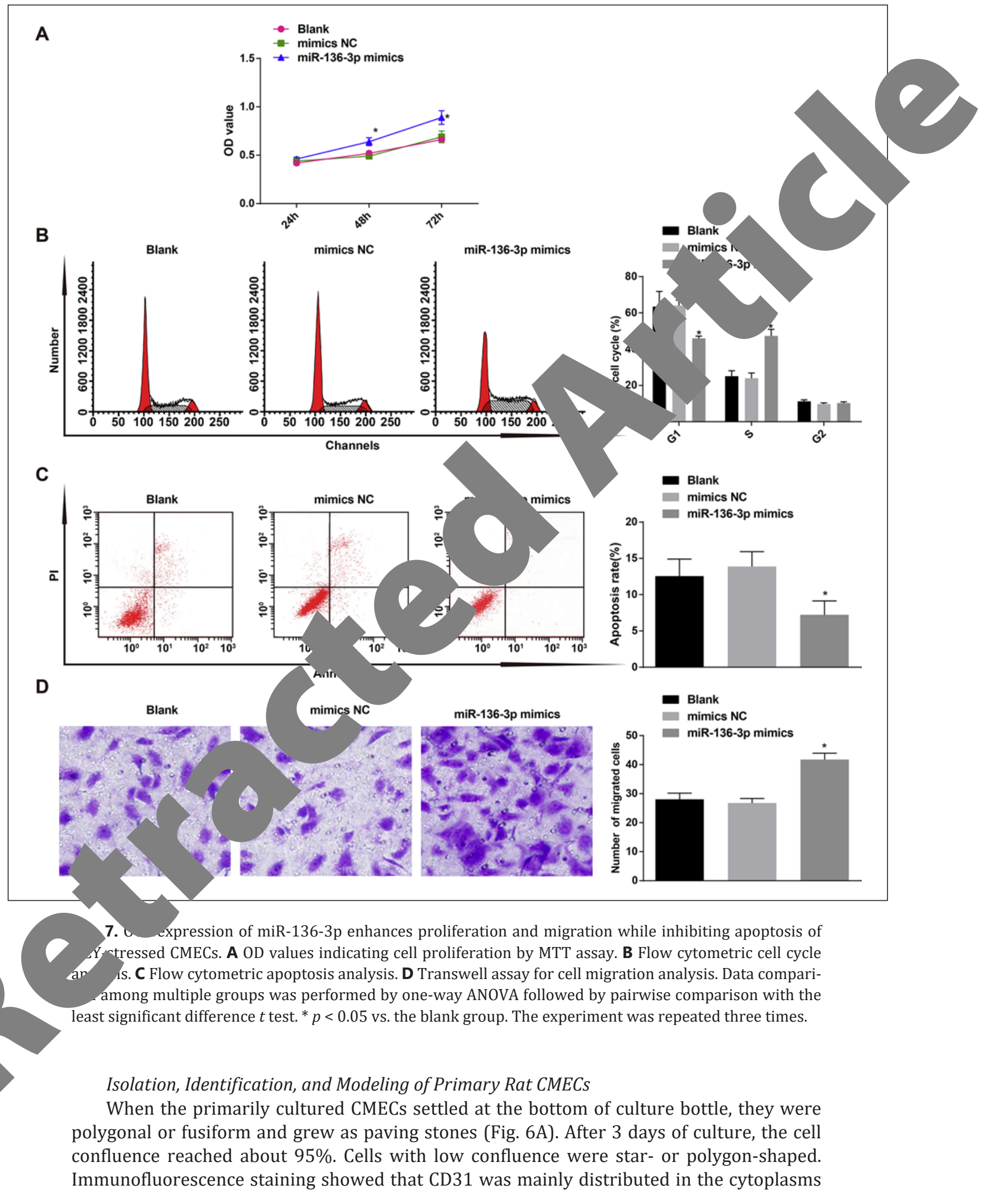




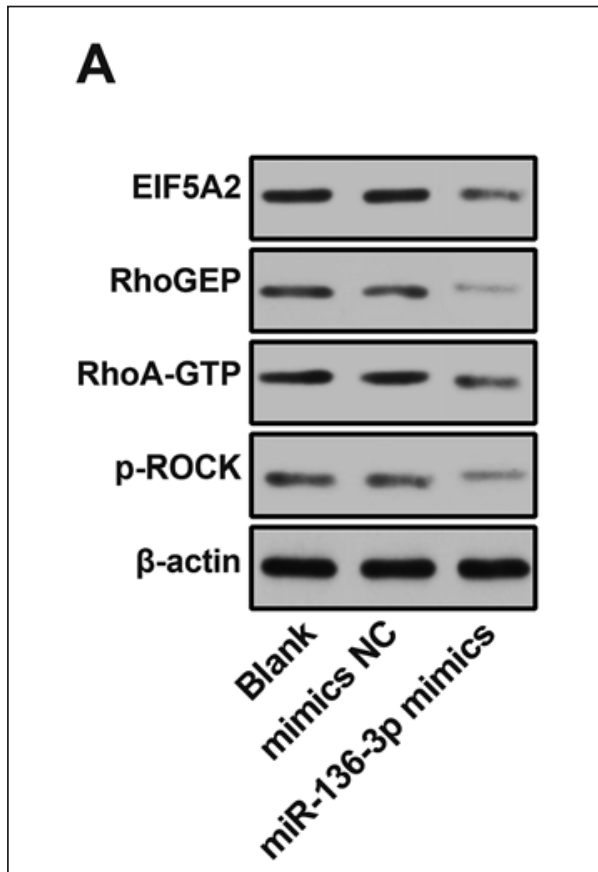

\section{B}

Fig. 8. MiR-136-3p inhibits EIF5A2 expression and the vitro. A Protein bands of EIF5A2, RhoGEP, RhoA-GTP EIF5A2, RhoGEP, RhoA-GTP, and p-ROCK in CMECs in was performed by one-way ANOVA followed ence test. ${ }^{*} p<0.05$ vs. the blank group. The
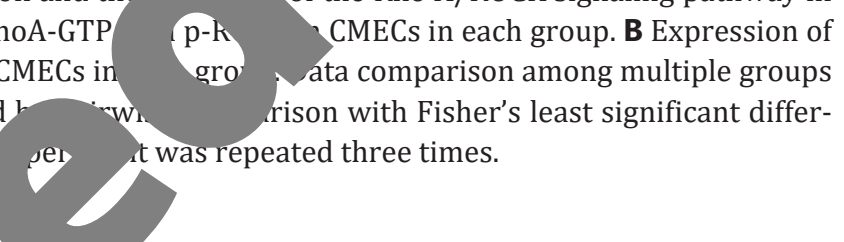
gro ata comparison among multiple groups rison with Fisher's least significant differper was repeated three times.

with red fluorescence (Fig. 6 suggested that relatively pure CMECs can be obtained following primary culture

The expression of $n$ co-incubated with HCY fo of miR-136-3p y the mimics NC $y$ CMECs $(p, 0.05$ he

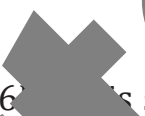
sub. experiments.

136-3p was determined by RT-qPCR (Fig. 6C). Rat CMECs were ${ }_{\mathrm{F} C}$ jury models. Relative to unstressed CMECs, the expression in HCY-stressed CMECs $(p<0.05)$. The blank group and he atment of miR-136-3p mimics elevated the expression of miR136-3p i $\quad 1$-st CMECs $(p<0.05)$. These above-mentioned results indicated that the miR-130 xpression was successfully intervened.

rexpresion of miR-136-3p Enhances Proliferation and Migration while Inhibiting is of HCY-Stressed CMECS

MTT assay was employed to assess the inhibitory effect of miR-136-3p on the proliferati Of CMECs (Fig. 7A). The OD values of CMECs showed no pronounced difference at $24 \mathrm{~h}$ ach group $(p>0.05)$. After 48 and $72 \mathrm{~h}$ of CMEC culture, the cell proliferation was not significantly different in the mimics NC group $(p>0.05)$, which was increased in the miR136-3p mimics group $(p<0.05)$ versus the blank group. Compared with cell proliferation at $24 \mathrm{~h}$, the cell proliferation of each group was facilitated at $48 \mathrm{~h}$ and $72 \mathrm{~h}(p<0.05)$. Compared with cell proliferation at $48 \mathrm{~h}$, the cell proliferation of each group was also accelerated at $72 \mathrm{~h}(p<0.05)$. In conclusion, miR-136-3p resulted in enhanced proliferation of CMECs.

The cell cycle distribution was evaluated by PI single staining assay (Fig. 7B). Compared with the blank group, no pronounced difference was identified in the proportion of cells arrested at the G1, S, and G2 phases in the mimics NC group (all $p>0.05$ ). Compared with the 
A
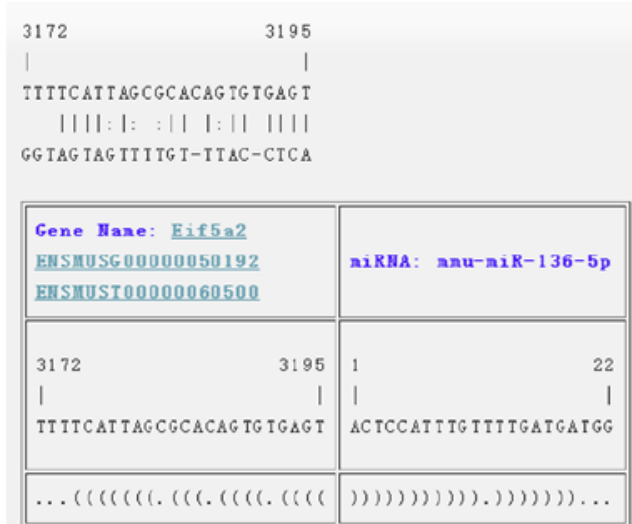

B

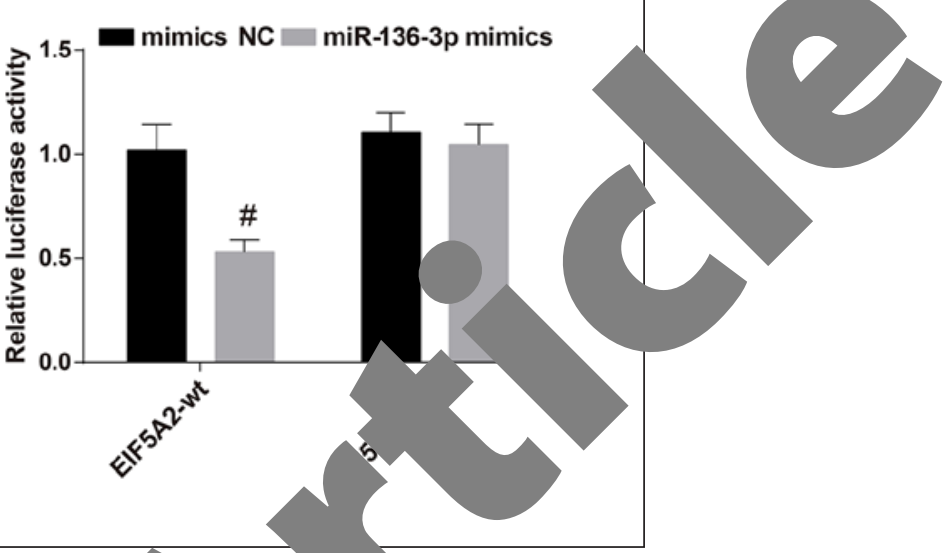

Fig. 9. EIF5A2 is a target gene of miR-136-3p. A Bioinformatic pre bindir cs of miR-136-3p and EIF5A2. B Luciferase activity measured by dual luciferase re r a among multiple groups was performed by one-way ANOVA followed least significant difference test. ${ }^{\#} p<0.05$ vs. the mimics ${ }^{\prime \prime}$ group. The nparison with Fisher's ment was repeated three times.

blank group, the cells arrested at the G1 p decreased, accompanied by increased cells in

The cell apoptosis conditions were (Fig. 7C). There was no significant diff and the mimics NC group $(p>0,05)$. Tl rate than the blank group $(p$

Transwell migration ass? differ significantly betwe with the blank group a mimics group was enhai the mimics NC group, the migration ability of the miR-136-3p 7D) demonstrated that, the cell migration ability did not CIy the apoptosis rate between the blank group 1.3 $3 \mathrm{p}$ mimics group displayed lower apoptosis sph miR-136-3p mimics group were soth $p<0.05$. (n 05).

miR-136-3 F5A2 Expression and the Activation of the Rho A/ROCK Signaling

Pathwe in vi

Wes' blot sis was adopted to measure the expression of EIF5A2 and the activation su fo the Rho A/ROCK signaling pathway in CMECs (Fig. 8A, B). In comparison with nk g, the expression of EIF5A2, RhoGEP, RhoA-GTP, and p-ROCK in the mimics NC ras nou orgnificantly different (all $p>0.05$ ), while the expression of these factors in the iR- mimics group was diminished (both $p<0.05$ ). This indicates that upregulation

iR-136-3p can repress the expression of EIF5A2 and inactivate the Rho A/ROCK signaling $\mathrm{a}^{+}$ay in stressed CMECs in CAD.

EIF5A2 Is a Target Gene of miR-136-3p

The bioinformatics analysis predicted that miR-136-3p could directly target sequences that bind to the 3'-UTR region of EIF5A2 (Fig. 9A, B). The luciferase activity of cells co-transfected with EIF5A2-WT and miR-136-3p mimics was lower than that of cells co-transfected with EIF5A2-WT and mimics NC $(p<0.05)$. There was no significant difference in the luciferase activity of cells co-transfected with EIF5A2-MUT and mimics NC, compared with that of cells co-transfected with EIF5A2-MUT and miR-136-3p mimics $(p>0.05)$. The aforementioned results suggested that miR-136-3p targeted and regulated the 3'-UTR of EIF5A2. 


\section{Kidney \\ Blood Pressure \\ Research}

\begin{tabular}{l|l}
\hline Kidney Blood Press Res 2020;45:477-496 \\
\hline DOI: 10.1159/000505849 & $\begin{array}{l}\text { ○ 2020 The Author(s). Published by S. Karger AG, Basel } \\
\text { www.karger.com/kbr }\end{array}$ \\
\hline
\end{tabular}

Lin et al.: Functional Relevance of miR-136-3p in CAD

\section{Discussion}

Recent studies have suggested that multiple miRNAs are implicated in the pathophysiology of CAD as well as the presentations including myocardial infarction and heart failure $[25,26]$. Thus, characterizing the functional relevance of related miRNAs may lead to a bet understanding of pathogenesis and provide new insights into diagnosis and prognosis of CAD Besides, abnormal signaling of vascular endothelial cells has been reported to be a contribut to such common diseases as CAD, atherosclerosis, and hypertension $[27,28]$. The activiti CMECs have significant roles to play during the progression of CAD, which ha een i sively investigated $[29,30]$. Furthermore, a prior study has reported that proinf ma. cytokines are independent risk factors associated with CAD due to the key ole of rade inflammation in the pathogenesis of CAD [31,32]. Therefore, this study $w_{c}$ forme $h$ the aim of delineating the function of miR-136-3p during the progression esnecrally in the oxidative stress and inflammatory response and CMEC beha sol for HCYinduced stress.

It is worthy to report that miR-136-3p was downregula the myo al tissue of CAD rats and CAD-stressed CMECs. Very little research has 1 so he e $\lambda_{1}$ 'ession of miR136-3p in human or experimental CAD. A previous study on $r$ has indicated that miR-136 was abnormally expressed in vascular smooth muscle , and its alteration mediates atherosclerosis through the influence on cell seration [1 nd ssc-miR-136 has been reported to be broadly decreased in the myocard. ve of pig with coronary microembolization [33]. In this current study, we revealer an rulation of miR-136-3p diminished the cardiomyocyte apoptosis in CAD rat mode s evi ed by lowered cleaved-caspase-3 and Bax as well as increased expression of $0^{-1}-2$. studies have demonstrated the functional relevance of miRNAs to CAD an 0 festanons. For example, a study has revealed that the amplification of miR-136 w rotect from hypoxia induced apoptosis of vascular endothelial cells [15 d, it has been identified that the alteration of miR-136 mediates the athero is through the influence on cell proliferation [14].

The in vivo experim of sent study also revealed that overexpressed miR136-3p augmented the $c$ ac function and ameliorate pathological damage in the myocardial tissue of CAD rats. More the overexpression of miR-136-3p acted to reduce the oxidative stress flan response in CAD rats, as reflected by upregulated SOD content and de dP MDA content, reduced serum levels of CK-MB, cTnI, IL-1 $\beta$, IL-6 and TNF- $\alpha$ ad $\mathrm{n}$ on alminished mRNA expression of IL-1 $\beta$, IL-6, and TNF- $\alpha$. Evidence has beer sent how that the levels of biomarkers associated with oxidative stress have the city to predict the risk of CAD as well as adverse cardiovascular outcomes [34, st as nson and Koenig [36] reported, multiple markers related to the systemic ation ould serve as effective indicators predicting the cardiovascular events, which ay $\mathrm{b}$ Led in the management of CAD. A study by Zhong et al. [37] has documented that her expression of miR-136-5p could suppress the inflammation in response to oxygenst e deprivation and reoxygenation-treated PC-12 cells. Accordingly, lower expression of -136-3p may show inverse correlation with serum levels of CK-MB, cTnI, IL-1 $\beta$, IL-6, and TNF- $\alpha$, subsequently with oxidative stress and inflammatory response in CAD rats. It is also significant to note that overexpressed miR-136-3p caused remarkable increase in proliferation and migration, accompanied by diminished apoptosis of HCY-stressed CMECs. These findings were largely consistent with a previously conducted study, where the treatment of miR-136 mimics protected neurocytes against injury that was induced by hypoxia in a spinal cord ischemic injury rat model [38].

Importantly, the targeting relationship of miR-136-3p and EIF5A2 was determined based on bioinformatics prediction and luciferase activity assay. Besides, miR-136-3p was shown 
to repress the activation of EIF5A2 and the Rho A/ROCK signaling pathway. Multiple studies have established ROCK as a major downstream effector of the small GTP-binding protein Rho, and it is a significant mediator of angiogenesis and angiogenesis-related disorders $[39,40]$. EIF5A2 is a downstream target of Akt [41], and the ROCK signaling shared the activation status with the PI3K/Akt/ROCK pathway [42]. The Rho/ROCK interaction has been im? cated in the occurrence of atherosclerosis due to the function exerted in vascular smoot. muscle cells, the inflammatory responses, and endothelial function [21]. Thus, the myocardi-1 injury induced by injection of pituitrin or the HCY-induced stress in CMECs could be inhil when the expression of EIF5A2 and the activation of the Rho A/ROCK signaling hway inhibited by the overexpression of elevated miR-136-3p.

The findings of this study revealed a protective effect of miR-136-3p ar in ${ }^{\circ} \mathrm{m}_{\mathrm{a}}$, dial injury in CAD rat models and CMECs through the inhibition on EIF5A2 an tho A $K$ signaling pathway. The evidence provided by the study supports the starce heregulation of miR-136-3p is likely to present as a new target in the treatme of $\mathrm{CA}$ wever, the research focusing on the role of miR-136-3p in CAD is relatively $\mathrm{d}$, which may lead to insufficient data and reference materials. Still, future in ations a a to extend myocardial injury in CAD to other factors.

\section{Acknowledgement}

We would like to acknowledge the review

\section{Statement of Ethics}

All animal experiments $y$ Chinese and Western Medicir for the Administration of irs 6 pro Ethics Committee of Hospital of Traditional bei Province and are in accordance with the Regulations minimize the suffering o animals included in the study.

\section{Author Contributions}

Guarantor of the integrity of the entire study: Yongbo Lin, Jinguo Lu; study design: Yongbo Lin, Hanliang Dan; literature research: Hanliang Dan, Jinguo Lu; experimental studies: Yongbo Lin, Hanliang Dan, Jinguo Lu; data analysis: Yongbo Lin, Hanliang Dan, Jinguo Lu; manuscript editing: Yongbo Lin, Hanliang Dan; manuscript review: Yongbo Lin, Jinguo Lu. 
Kidney

Blood Pressure

Research

\begin{tabular}{l|l}
\hline Kidney Blood Press Res 2020;45:477-496 \\
\hline DOI: 10.1159/000505849 & $\begin{array}{l}\text { @ 2020 The Author(s). Published by S. Karger AG, Basel } \\
\text { www.karger.com/kbr }\end{array}$ \\
\hline
\end{tabular}

Lin et al.: Functional Relevance of miR-136-3p in CAD

\section{References}

1 Jokinen E. Obesity and cardiovascular disease. Minerva Pediatr. 2015 Feb;67(1):25-32.

2 Zhang HW, Zhao X, Guo YL, Zhu CG, Wu NQ, Sun J, et al. Free fatty acids and cardiovascular outcome: a Chinese cohort study on stable coronary artery disease. Nutr Metab (Lond). 2017 Jun;14(1):41.

3 Tully PJ, Cosh SM, Baune BT. A review of the affects of worry and generalized anxiety disorder upon card vascular health and coronary heart disease. Psychol Health Med. 2013;18(6):627-44.

4 Van Camp G. Cardiovascular disease prevention. Acta Clin Belg. 2014 Dec;69(6):407-11.

5 Heslop CL, Tebbutt SJ, Podder M, Ruan J, Hill JS. Combined polymorphisms in oxidative stress genes pred coronary artery disease and oxidative stress in coronary angiography patients. Ann Hum Genet. 2012 76(6):435-47.

6 Swardfager W, Herrmann N, Cornish S, Mazereeuw G, Marzolini S, Sham L, et al. Exercise inflammatory markers in coronary artery disease: a meta-analysis. Am Heart J. 2012 Apr;163(4)

7 Leong DP, Joseph PG, McKee M, Anand SS, Teo KK, Schwalm JD, et al. Reducing the Glo" vascular Disease, Part 2: Prevention and Treatment of Cardiovascular Disease. Circ 695-710.

8 Felekkis K, Touvana E, Stefanou C, Deltas C. microRNAs: a newly described class of play a role in health and disease. Hippokratia. 2010 0ct;14(4):236-40.

9 Bartel DP. MicroRNAs: target recognition and regulatory functions. Cell. $2009 \mathrm{~J}$

10 Small EM, Olson EN. Pervasive roles of microRNAs in cardiovascul ? hiology. Nà 336-42.

11 Mendell JT, Olson EN. MicroRNAs in stress signaling and human c

12 Jansen F, Yang X, Proebsting S, Hoelscher M, Przybilla D, Baumann K microvesicles predicts cardiovascular events in patients with coronat Oct;3(6):e001249.

13 Mehta R, Otgonsuren M, Younoszai Z, Allawi H, Ray non-alcoholic fatty liver disease and coronary artery dis

14 Zhang CF, Kang K, Li XM, Xie BD. MicroRNA-136 Pr ERK1/2 Pathway by Targeting PPP2R2A in Atheros

15 Zhang BY, Jin Z, Zhao Z. Long intergenic noncodin induced apoptosis of vascular endothelial cellc Riom

16 He J, Zhao J, Peng X, Shi X, Zong S, Zeng G. IL-17-Mediated Inflammatory Response Kitahara Y, Nakamura K, Kogur K, Mine hormone-human chorionic go

18 Jou J, Diehl AM. Epithelial-mese 1031-4.

19 Tang DJ, Dong SS, Ma NF, Y cell motility and promot 63.

20 Chen Z, Yu T, Zhorn inhibit bladde

21 Dong M, Yar vasosparn. Card Chen SI X, new simple method for isolation of microvascular osis. $\quad$ sc Pharmacol. 2015;13(3):405-12.

A 00 ponges miR-136 to regulate the hypoxia cother. 2017 Oct; $94: 238-43$. m of MiR-136-5p Targeting NF-кB/A20 in the
ry. Cell Physiol Biochem. 2017;44(3):1224-41. Re f microRNA-136-3p on the expression of luteinizing ANA in rat ovaries. Biol Reprod. 2013 Nov;89(5):114.

\section{in 1} il trans..... and hepatocarcinogenesis. J Clin Invest. 2010 Apr;120(4):

n. Chen $\_$al. Overexpression of eukaryotic initiation factor 5A2 enhances mor metastasıs in hepatocellular carcinoma. Hepatology. 2010 Apr;51(4):1255-<smiles>C1CCCCC1</smiles>

, et al. $\mathrm{Mg}(\mathrm{II})$-Catechin nanoparticles delivering siRNA targeting EIF5A2 gruwen in vitro and in vivo. Biomaterials. 2016 Mar;81:125-34.

rrent status of rho-associated kinases (ROCKs) in coronary atherosclerosis and

new simple method for isolation of microvascular endothelial cells avoiding both

2. nang ne Li G, Ke D. Ghrelin stimulates angiogenesis via GHSR1a-dependent MEK/ERK and PI3K/Akt

nal pa in rat cardiac microvascular endothelial cells. Peptides. 2012 Jan;33(1):92-100.

ng L, Fe , He G, Jing T. Knockdown of Nrf2 inhibits the angiogenesis of rat cardiac micro-vascular endos under hypoxic conditions. Int J Biol Sci. 2013 Jul;9(7):656-65.

M, van der Lans CA, Halvorsen B, Gullestad L, Kuiper J, Aukrust P, et al. The peripheral blood mononuclear cell microRNA signature of coronary artery disease. Biochem Biophys Res Commun. 2010 Apr;394(3): 2-7.

apageorgiou N, Tousoulis D, Charakida M, Briasoulis A, Androulakis E, Tentolouris C, et al. Prognostic role of miRNAs in coronary artery disease. Curr Top Med Chem. 2013;13(13):1540-7.

27 Heusch G, Libby P, Gersh B, Yellon D, Böhm M, Lopaschuk G, et al. Cardiovascular remodelling in coronary artery disease and heart failure. Lancet. 2014 May;383(9932):1933-43.

28 Xiong Y, Wang L, Jiang W, Pang L, Liu W, Li A, et al. MEF2A alters the proliferation, inflammation-related gene expression profiles and its silencing induces cellular senescence in human coronary endothelial cells. BMC Mol Biol. 2019 Mar;20(1):8.

29 Yu H, Kalogeris T, Korthuis RJ. Reactive species-induced microvascular dysfunction in ischemia/reperfusion. Free Radic Biol Med. 2019 May;135:182-97.

30 Yan P, Sun C, Ma J, Jin Z, Guo R, Yang B. MicroRNA-128 confers protection against cardiac microvascular endothelial cell injury in coronary heart disease via negative regulation of IRS1. J Cell Physiol. 2019 Aug;234(8): 13452-63. 
31 Kaptoge S, Seshasai SR, Gao P, Freitag DF, Butterworth AS, Borglykke A, et al. Inflammatory cytokines and risk of coronary heart disease: new prospective study and updated meta-analysis. Eur Heart J. 2014 Mar;35(9): 578-89.

32 Chae CW, Kwon YW. Cell signaling and biological pathway in cardiovascular diseases. Arch Pharm Res. 2019 Mar;42(3):195-205.

33 Su Q, Li L, Zhao J, Sun Y, Yang H. MiRNA Expression Profile of the Myocardial Tissue of Pigs with CoronMicroembolization. Cell Physiol Biochem. 2017;43(3):1012-24.

34 Stephens JW, Gable DR, Hurel SJ, Miller GJ, Cooper JA, Humphries SE. Increased plasma markers of oxidative stress are associated with coronary heart disease in males with diabetes mellitus and with 10 -year risk jr prospective sample of males. Clin Chem. 2006 Mar;52(3):446-52.

35 Tsimikas S, Brilakis ES, Miller ER, McConnell JP, Lennon RJ, Kornman KS, et al. Oxidized pho- holipids lipoprotein, and coronary artery disease. N Engl J Med. 2005 Jul;353(1):46-57.

36 Rosenson RS, Koenig W. Utility of inflammatory markers in the management of coronary artery Cardiol. 2003 Jul; 92(1 1A):10i-8i.

37 Zhong Y, Yu C, Qin W. LncRNA SNHG14 promotes inflammatory response induced by ce fusion injury through regulating miR-136-5p /ROCK1. Cancer Gene Ther. 2019 Jul;26C

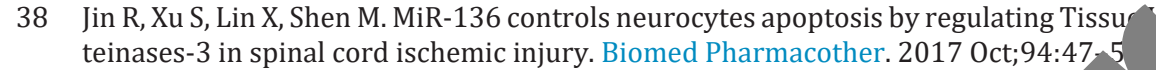

39 Liu J, Wada Y, Katsura M, Tozawa H, Erwin N, Kapron CM, et al. Rho-Associated Molecular Regulation of Angiogenesis. Theranostics. 2018 Nov;8(21 ‘ $453-69$.

40 Narumiya S, Thumkeo D. Rho signaling research: history, current s $\mathrm{s}^{+}$ Jun;592(11):1763-76.

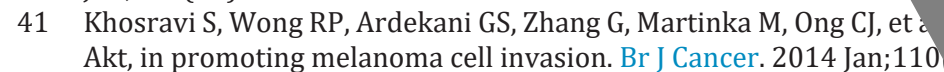

42 Tsoyi K, Chu SG, Patino-Jaramillo NG, Wilder J, Villal Doyle-Eisele ation-induced Pulmonary Fibrosis and Inhibits Fibro ctivation by via CD148. Am J Respir Cell Mol Biol. 2018 Feb;58(2):¿

\section{-Coil Kinase (ROCK) in}

FEBS Lett. 2018 citure dì 40 downstream target of al. Syndecan-2 Attenuates Radiating PI3K/Akt/ROCK Pathway 